\title{
Article \\ Monitoring of Radial Deformations of a Gravity Dam Using Sentinel-1 Persistent Scatterer Interferometry
}

\author{
Jannik Jänichen ${ }^{1, *}$, Christiane Schmullius ${ }^{1}$, Jussi Baade ${ }^{2} \mathbb{D}$, Katja Last ${ }^{3}$, Volker Bettzieche ${ }^{3}$ \\ and Clémence Dubois ${ }^{1}$
}

Citation: Jänichen, J.; Schmullius, C.; Baade, J.; Last, K.; Bettzieche, V.; Dubois, C. Monitoring of Radial Deformations of a Gravity Dam Using Sentinel-1 Persistent Scatterer Interferometry. Remote Sens. 2022, 14, 1112. https://doi.org/10.3390/ rs14051112

Academic Editors: Antonio Miguel Ruiz Armenteros, Roberto Tomás, Joaquim João Sousa, María Clara de Lacy and Zhenhong Li

Received: 10 January 2022

Accepted: 16 February 2022

Published: 24 February 2022

Publisher's Note: MDPI stays neutral with regard to jurisdictional claims in published maps and institutional affiliations.

Copyright: (C) 2022 by the authors. Licensee MDPI, Basel, Switzerland. This article is an open access article distributed under the terms and conditions of the Creative Commons Attribution (CC BY) license (https:// creativecommons.org/licenses/by/ $4.0 /)$.
1 Department for Earth Observation, Institute of Geography, Friedrich Schiller University Jena, Löbdergraben 32, 07743 Jena, Germany; c.schmullius@uni-jena.de (C.S.); clemence.dubois@uni-jena.de (C.D.)

2 Department for Physical Geography, Institute of Geography, Friedrich Schiller University Jena, Löbdergraben 32, 07743 Jena, Germany; jussi.baade@uni-jena.de

3 Department for Water Economy, Ruhrverband, Kronprinzenstr. 37, 45128 Essen, Germany; kla@ruhrverband.de (K.L.); bettzieche@damsafety.eu (V.B.)

* Correspondence: jannik.jaenichen@uni-jena.de

\begin{abstract}
Dams have many important socio-economic functions, fulfilling roles ranging from storing water to power generation, but also serving as leisure areas. Monitoring of their deformation is usually performed using time-consuming traditional terr estrial techniques, leading to a yearly monitoring cycle. To increase the monitoring cycle, new methods are needed. Persistent Scatterer Interferometry (PSI) is a well-established technique for monitoring millimeter deformation of the Earth's surface. The availability of free and open SAR data with a repeat cycle of 6 to 12 days from the Copernicus mission Sentinel-1, allows PSI to be used complementary to traditional surveying techniques. This present study investigates deformation dynamics at the Moehne gravity dam in North Rhine-Westphalia, Germany. The applicability of the PSI technique to the deformation monitoring of dams is evaluated, in relation to the necessary accuracy requirements. For this purpose, Sentinel-1 data from January 2015 to November 2020 are analyzed and the deformation estimates are assessed with in situ information. Using a precise dam model, the radial deformation of the dam could be extracted and compared to trigonometric and plumb measurements. The first results show that the movements of the Moehne dam follow a seasonal pattern, reaching a maximum radial deformation of up to $4 \mathrm{~mm}$ in Spring, following a decline to $-4 \mathrm{~mm}$ in the late summer. RMSE between $1.1 \mathrm{~mm}$ and $1.5 \mathrm{~mm}$ were observed between the PSI observations and the in situ data, showing that the PSI technique achieves the necessary accuracy requirements for gravity dam monitoring from space.
\end{abstract}

Keywords: InSAR; PSI; Sentinel-1; deformation monitoring; accuracy assessment

\section{Introduction}

Dams are defined as massive barrier structures made of masonry or concrete [1] and are subdivided into different categories according to the type of load-bearing behavior. Gravity dams, such as the Möhne dam [2], are the most used type of dam in Germany and are characterized by having a triangular cross-section, thus transmitting the horizontally acting water force into the subsoil through their own weight [1]. Gravity dams are subjected to different kinds of deformation, including vertical settling, which can occur after construction, and horizontal deformation in the radial direction to the dam crest in a seasonal cycle, depending on temperatures and the water level of the reservoir [3]. Even if such deformations are permissible up to a certain amount defined by the structural engineering calculation, they must be monitored regularly to ensure the long-term stability of the dams. An extensive measuring program is usually set up, which records both the short- and the long-term behavior of the deformation [4]. For absolute vertical displacements measurements, geodetic methods such as tacheometry and leveling are used [4]. 
In addition, relative horizontal displacements and deformations are determined by plumb bob measurements. These terrestrial measurements facilitate the evaluation of the dam deformation in accordance with German standards (DIN 19700-10 (2004)) [5]. In the particular case of gravity dams, the precision of the measurements should be at least $+/-2 \mathrm{~mm}$, which is guaranteed by the terrestrial measurements [6]. However, such measurements are highly time-consuming and the monitoring of dams by trigonometry occurs mostly once or twice a year, which makes the observation of seasonal changes difficult.

Technical advances in differential synthetic aperture radar interferometry, or DInSAR, allow for the identification and characterization of such deformations. Specifically, the Persistent Scatterer Interferometry technique, or PSI [7,8], allows for the estimation of the deformation of a particular scatterer with millimeter accuracy. The PSI technique has already been used successfully for the monitoring of various embankment dams in different studies [9-18]. For example, the Plover Cove Dam in Hong Kong was investigated from 2008 to 2012 using TerraSAR-X data [13]. Other examples include the Charvak Dam in Uzbekistan and the Three Gorges Dam in China [14,15]. Another study is monitoring the deformations of the La Viñela dam in Málaga, southern Spain using Sentinel-1 data [16]. Furthermore, the Mosul Dam in Iraq, which is in danger of failure, is an intensively studied object $[11,17,18]$. Water intrusion into the easily soluble evaporite layers beneath the dam has been observed since its construction in 1984 and monitoring by on-site measurements has not been possible [17]. Here, the application of PSI technology provided an alternative that made it possible to observe the deformations [17]. The feasibility of PSI analysis using embankment dams and gravity dams as an example was detailed in particular in [19]. These insights can be used as a guideline for analyses to be performed in the future. Similar objects to dams being monitored with the PSI technique are locks, as in the example of the lock located in Hessigheim am Neckar in Germany [20]. The X-band data in both recording geometries (ascending and descending) were used. Due to the high geometrical resolution, a very high number of PS points could be identified, whose movements could primarily be traced back to a vertical deformation component [20]. Moreover, the results showed a motion profile that could be traced back to an annual cycle of movements. Further examples of PSI-based monitoring of dams are also shown in [21,22].

In comparison with embankment dams, the observation of gravity dams using the PSI technique, or other multi-temporal synthetic aperture radar interferometry (MTInSAR) techniques, has not yet been documented in the literature in detail. This is surprising because gravity dams are heavily stressed due to various factors such as temperature or water-level changes, which result in annual radial movements (transverse to the water load) in the range of millimeters. Additional research needs concern a sufficient accuracy and reliability analysis, which is often not possible due to missing in situ data [14,23]. However, this is essential in order to evaluate the potential and possibility of an automatic use of the PSI technique for dam monitoring. A first analysis regarding the accuracy of the PSI technique for the monitoring of embankment dams has been performed by also including data from the nationwide Ground Motion Service Germany (BBD) [24]. Further studies are yet required to assess the sufficient accuracy of the PSI technique for gravity dams.

In this study, the use of spaceborne persistent scatterer interferometry (PSI) for temporally dense regular monitoring of the deformation of a gravity dam is investigated. Two particular goals were set in this study. The first and most fundamental goal is to successfully assess and validate the use of the PSI technique for gravity dams. In particular, an examination of whether accuracy requirements for gravity dam monitoring according to German standards are fulfilled with spaceborne SAR data is performed, considering the precision of radial deformations. The second goal is to investigate the impact of the observation cycle on the position and number of detected PS points in order to iterate solutions for an automatic monitoring of dams using PSI. Specifically, the preferable observation cycle with respect to the accuracy requirements [5] for monitoring, number of observation points and accuracy of the estimated deformation is investigated. As gravity dams have not been 
included in the monitoring of deformations with PSI, this study intends to set a basis for the deformation of gravity dams.

\section{Materials and Methods}

In particular, in order to assess and validate the use of the PSI technique for gravity dams, whether the accuracy requirements for gravity-dam monitoring can be fulfilled with spaceborne SAR data was investigated according to the German Institute for Standardization (DIN) [5]. To this end, the resulting satellites' Line of Sight (LOS) deformations of the computed PS points were converted into horizontal deformations using trigonometric principles, to be comparable to the in situ measurements. Subsequently, the use of the precise dam model of the Moehne gravity dam is used to estimate radial deformation information. To investigate the impact of the observation cycle on the position and number of detected PS points in order to iterate solutions for the automatic monitoring of dams using PSI, three different data sets were created, considering a different number of acquisitions within the same period of observation.

In this chapter, the study area, the data that were used, and the applied methods are described, starting with the study area.

\subsection{Study Area}

In this study, the Moehne Dam, located in the east of the state North Rhine-Westphalia in western Germany, was investigated. The location is shown in Figure 1a.

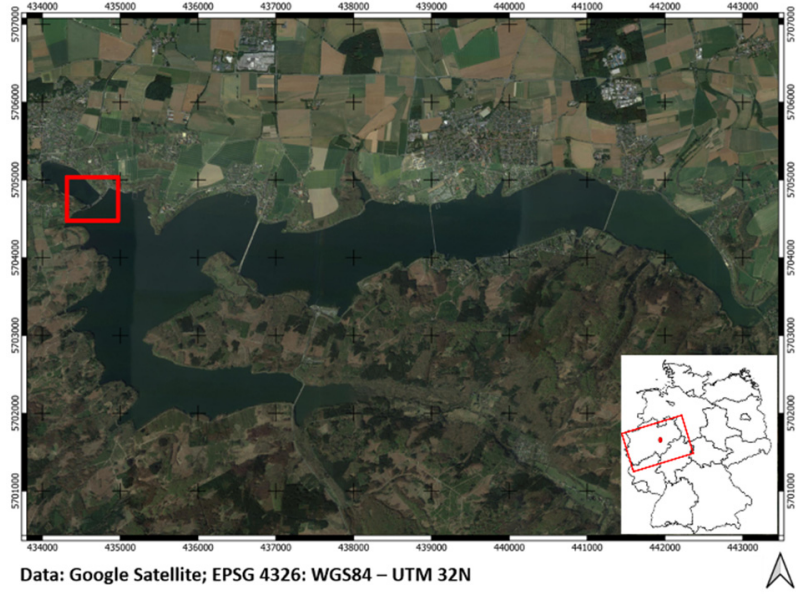

(a)

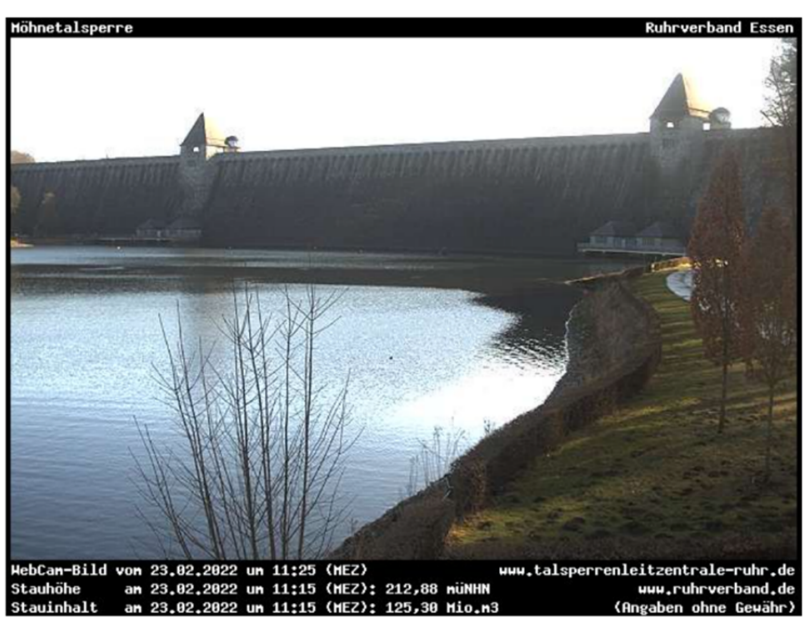

(b)

Figure 1. Study area of this investigation: (a) Moehne Lake in Western Germany. The position of the Moehne Gravity Dam and the Sentinel-1 coverage are marked in red; (b) Photo of the Moehne Gravity Dam (Ruhrverband 2022) [25].

The Moehne Dam is a gravity dam made of quarry masonry, striking north-east to the south-west with its reservoir to the east [2]. The reservoir has a full supply capacity of 134.5 million $\mathrm{m}^{3}$ of water and contributes significantly to securing the water supply of the Ruhr area [26]. Below the Moehne dam lies the so-called compensatory pond, which is visible in Figure 1b. It serves to equalize the release of water from the Moehne reservoir into the lower reaches, as the main power plant only uses the water from the Moehne reservoir for electricity generation on an hourly basis [26].

The dam includes two pre-dams [27] and an area of $43,637 \mathrm{~km}^{2}$ is covered by the Moehne reservoir [26]. The annual mean long-term precipitation for the period between 1931 and 2012 was $857 \mathrm{~mm}$ [26]. The Moehne dam was built between 1908 and 1912 ([28], severely damaged in an air raid in 1943 and rebuilt by October 1943 [26]. The $650 \mathrm{~m}$ long and $40 \mathrm{~m}$ high masonry dam [2] is shown in Figure 1b. Despite its arch shape, it gets its stability as a gravity dam from the triangular cross-section and the weight of the masonry. Moreover, 
the surrounding topography and the fact that the dam is being regularly monitored with terrestrial measurements (see Section 2.2), makes it an ideal monitoring object.

\subsection{Data}

For the analysis, both satellite data from the Copernicus Sentinel- 1 mission and in situ data were used. Table 1 lists the Sentinel- 1 data used for the analysis. In the case of a big object such as the dam of the Moehne reservoir, some areas may not be visible for the radar antenna due to the incidence angle of the signal, which results in shadow areas (see Figure $1 \mathrm{~b}$ for an overview of the dam). Geometric distortions due to other geometric factors such as slope and aspect can also occur and hamper the correct detection of PS points [29]. Regarding these geometric properties, the so-called R-index was developed [30]. It indexes the identifiability of PS points purely on the geometric properties. A digital elevation model (DEM) provides essential information, from which slope, aspect, and incidence angle are calculated [30]. The aspect in the case of dams is mainly determined by their geographical orientation. In the case of the Moehne dam, the northeast to southwest orientation defines the aspect angle of the airside to the west and of the waterside to the east. With its location in the geographical space and the resulting alignment angles, the Moehne dam provides good geometric conditions for a PSI analysis based on Sentinel-1 acquisitions in the ascending orbit. Due to the geographical orientation of the Moehne dam, an analysis utilizing data from the descending orbit is not expected to deliver a sufficient number of PS points. This relation is demonstrated in Figure 2, whereby a radar signal from the descending orbit would reach the dam on the waterside, where the dam's impact area is low and changes in water level occur. The ascending orbit, on the other hand, provides much more beneficial conditions, since the radar signal reaches the airside, and the impact area is much bigger as well.

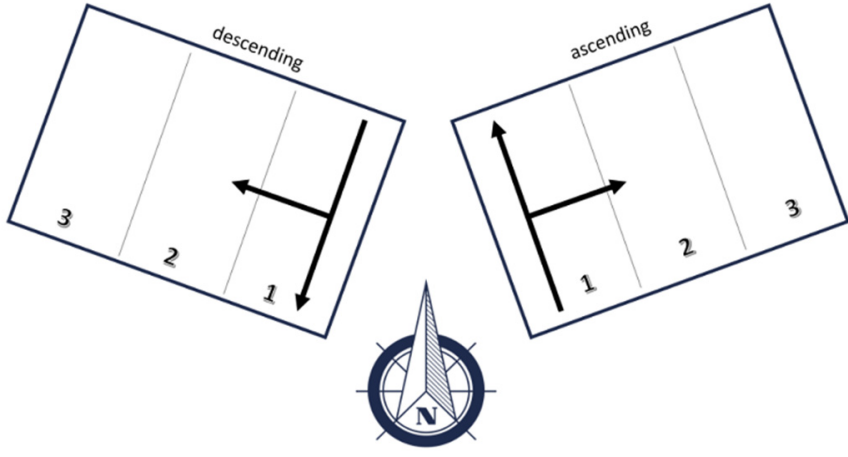

(a)

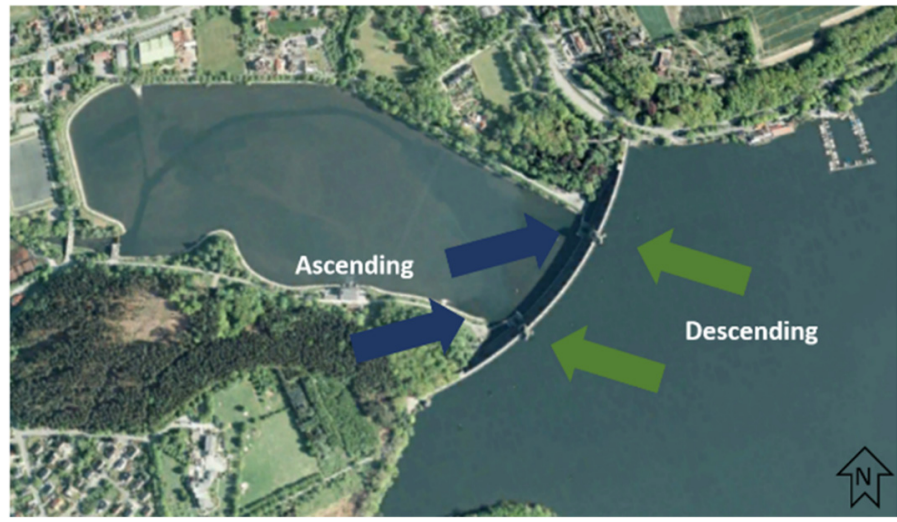

(b)

Figure 2. Study area of this investigation: (a) Descending and ascending flight directions of Sentinel-1; (b) Photo of the Moehne Gravity Dam [31].

The timeline of the study covers a period from March 2015 to March 2020. In ascending configuration, three data stacks, each containing a different number of scenes, were created. For this analysis, only data from Sentinal-1A were used. All data sets cover the same period, with the first data stack containing 38 Sentinel- 1 scenes $\left(t_{1}\right)$, the second data stack containing 67 scenes $\left(t_{2}\right)$, and the third data stack containing 164 scenes $\left(t_{3}\right)$. These correspond to a quarter, half and the full temporal availability of the data, respectively. All three stacks were used in separate PSI analyses in order to investigate the impact of the number of scenes on the resulting PSI accuracy and number of PS points, as well as their position. The data were acquired with an incidence angle of $39.4^{\circ}$ at the dam position. 
Table 1. Sentinel-1 data that were used in this study and their attributes. All three datasets originate from the same track and frame and use the same observation period, only the number of scenes differs.

\begin{tabular}{ccccc}
\hline Observation Period & Track/Frame & Data Stack & Scenes & $\theta\left({ }^{\circ}\right)$ \\
\hline February 2015-November 2020 & $15 / 164$ & $\mathrm{t}_{1}$ & 38 & 39.4 \\
February 2015-November 2020 & $15 / 164$ & $\mathrm{t}_{2}$ & 67 & 39.4 \\
February 2015-November 2020 & $15 / 164$ & $\mathrm{t}_{3}$ & 164 & 39.4 \\
\hline
\end{tabular}

In addition to the Sentinel-1 data, a digital terrain model is necessary for PSI processing. For this analysis, a Lidar-DEM was obtained from the geodata infrastructure of the state of North Rhine-Westphalia [32]. The data are freely available and have a resolution of $1 \mathrm{~m}$. The DEM was transformed into radar geometry and used for pre-processing, which aims for the most precise coregistration of all Sentinel-1 data. These stacked data were subset onto the study area and used for further processing.

For the analysis of the accuracy of the PS deformation estimates, available terrestrial measurement data from the Moehne dam were used. They were recorded by the Ruhrverband and made available for this work [33]. Furthermore, Table 2 provides an overview of the supplied data.

Table 2. In situ data that were used for the accuracy analysis.

\begin{tabular}{cccc}
\hline Measurement & Measuring Points & Measuring Interval & Accuracy \\
\hline Plumb & 1 & daily & $+/-0.5 \mathrm{~mm}$ \\
Trigonometry & 27 & every 6 months & $+/-3 \mathrm{~mm}$ \\
\hline
\end{tabular}

Plumb measurements are provided on a daily basis in the dam's tangential and radial axis. This measurement has a measuring accuracy of $+/-0.5 \mathrm{~mm}$ and is performed at one single point in the middle of the dam. The location of the plumb measurement is given in Figure 3. Since the dam crest is, to some extent, moving similarly in all places situated at the same dam height, one plumb measurement is sufficient and representative for the long-term motion of the points situated on this horizontal plane, here on the top of the wall between the two towers (OP 44 to OP48 in Figure 3) [27]. A further study showed differences in the movement patterns for points that are located on the dam crest on a short time scale [34]. In this study, the plumb measurement is used for the comparison with all detected PS points. As such, the vertical position and respective deformation of the detected PSs on the dam wall can be better investigated. Furthermore, trigonometric measurements taken at 27 measuring points were provided, with a temporal resolution of six months and a measuring accuracy of $+/-3 \mathrm{~mm}$. This measurement's accuracy is significantly lower compared to the plumb measurement. They represent, however, the full three-dimensional displacement of the Moehne dam wall. Figure 3 displays the spatial distribution of all 27 measuring points of the trigonometric measurements across the dam. For the accuracy analysis, the trigonometric point with the shortest distance to the respective PS point was chosen. The accuracy analysis is described in detail in the following chapter.

Additionally, water level and weather records containing information about precipitation and air temperature were available for the whole study period. Details are listed in Table 3.

Table 3. Water level and weather record details.

\begin{tabular}{cccc}
\hline Measurement & Measuring Points & Measuring Interval & Measuring Unit \\
\hline Precipitation & 1 & daily & $\mathrm{mm}$ \\
Air temperature & 1 & daily & ${ }^{\circ} \mathrm{C}$ \\
Water level & 1 & daily & $\mathrm{m}$ \\
\hline
\end{tabular}




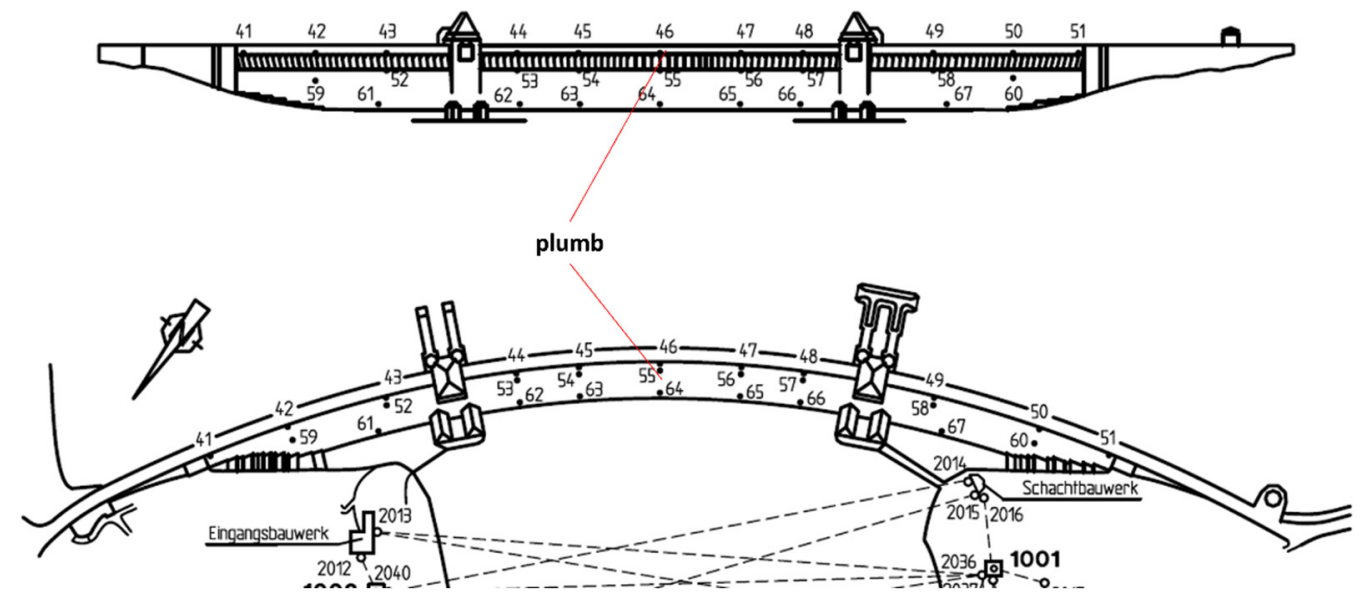

Figure 3. Spatial distribution of the trigonometric measurements (Object Points-OP) across the Moehne Gravity Dam. The 27 Object Points are numbered from 41 to 67 [2].

\subsection{Methods}

As mentioned in Section 1, this study aimed first at assessing the accuracy of Sentinel1 based PSI analysis on gravity dam monitoring and second at analyzing the impact of the observation cycle on the number, position, and accuracy of the detected PS and their displacements.

In particular, an examination of whether accuracy requirements for gravity dam monitoring according to the German Institute for Standardization (DIN) [5] are fulfilled with spaceborne SAR data was performed. Here, the resulting LOS deformations were transformed into horizontal deformations using trigonometric principles for comparison to the in situ measurements. Subsequently, a precise dam model of the Moehne gravity dam, allowing for the estimation of precise angles at each observation point, was used to estimate radial deformation information. PSI processing was performed with the GAMMA v1.8 software of the Swiss software company GAMMA Remote Sensing [35]. The PSI processing was performed for each ascending data stack presented in Section 2.1. separately, using the same parameters for PS candidate selection and processing. In order to reduce temporal decorrelation, a scene situated at the middle of the data stack and presenting good atmospheric conditions was chosen as the master for coregistration and processing (2 March 2017). This scene was available in all three data stacks. Additionally, a reference point was chosen by taking the criteria of a high phase stability with no present deformation into account. For the PSI analysis, a linear deformation model was used.

The determined deformation rates from the PSI analysis reflect the deformation in the LOS direction of the satellite. The imaging geometry results from the viewing direction and the incidence angle of the satellite. Therefore, the LOS displacement contains both the vertical and horizontal components of the displacements [36]. However, the vertical deformation at the Moehne gravity dam regularly measured by geometric leveling is negligible [27]. Therefore, the observed deformations can be attributed entirely to horizontal displacements. The horizontal motions can be extracted by projecting the LOS onto the horizontal plane, applying a simple trigonometric equation. This relation is shown in Figure 4.

The LOS deformation $\mathrm{d}_{\mathrm{LOS}}$ is the result of PSI processing, and since the incidence angle is known, horizontal deformations can be extracted using

$$
\mathrm{d}_{\text {hor }}=\mathrm{d}_{\mathrm{LOS}} * \sin (\theta) \text {, }
$$

where $d_{\text {hor }}$ defines the horizontal deformations and $\theta$ is the satellite's incidence angle. To achieve further comparability of the calculated PSI deformations with the in situ data recorded at the Moehne dam, additional trigonometric adjustments of the acquired horizontal movements are necessary, in order to project the displacements into the radial and 
tangential displacement component to the dam. As the tangential displacement is expected to be zero [27], the whole horizontal component is projected onto the radial axis to the specific dam position. This additional calculation is based on the difference of the heading angles $\mathrm{H}$ and the radial measurement angles $\mathrm{A}$ that were supplied by the Ruhrverband using the precise dam model. These adjustments are illustrated in Figure 5. The in situ measurement data are recorded in two different axes (red axes), whereby one axis is the movement of the tangential direction, which describes the movement along the dam's main axis at a particular point position (left-right movement). Furthermore, the radial axis is defined through the movements between the waterside and the airside at this very same point of the dam.

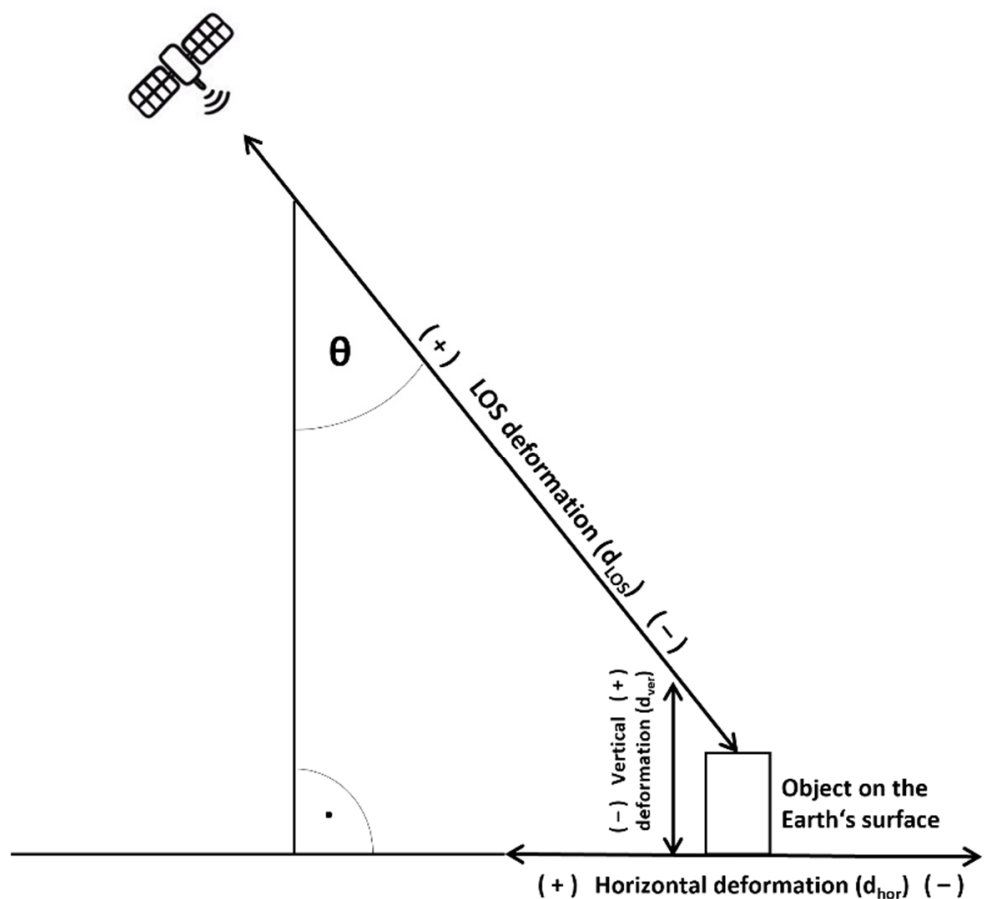

Figure 4. Illustration of the computation of the horizontal deformation in this study.

Both axes' orientations change for each location on the dam and, therefore, the angle $\mathrm{A}_{\text {rad }}$ between the absolute North and the radial axis changes as well. Furthermore, the horizontally projected LOS displacement of Sentinel-1 can be described using the heading angle of the satellite track, named here as $\mathrm{H}_{\text {asc }}$ for the ascending trajectory (simplified here as the angle between the absolute North and the flight direction). Both angles can be used to compute the angle $\alpha_{\mathrm{a}}$ using

$$
\alpha_{\mathrm{a}}=\mathrm{A}_{\mathrm{rad}}-\left|\mathrm{H}_{\mathrm{asc}}\right|,
$$

while $A_{\text {rad }}$ represents the given radial angle from the Ruhrverband. Then, $\alpha_{a}$ can be used to transform the horizontal deformations $\left(\mathrm{d}_{\text {hor }}\right)$ from the satellite's ascending axis into the radial movement axis $\left(\mathrm{d}_{\mathrm{rad}}\right)$ by applying

$$
\mathrm{d}_{\mathrm{rad}}=\mathrm{d}_{\text {hor }} * \cos \left(\alpha_{\mathrm{a}}\right) .
$$

By implementing these trigonometric adjustments to the original LOS displacements, the resulting radial movements are comparable to the available in situ measurements. Simple descriptive statistics were used to provide an assessment of the results and compare the computed radial PSI movements with the in situ measurements. For this purpose, 
the root mean square error (RMSE) and the correlation coefficient $\mathrm{r}^{2}$; were used. RMSE was computed by utilizing

$$
\operatorname{RMSE}=\sqrt{\frac{\sum_{\mathrm{t}=1}^{\mathrm{T}}\left(\mathrm{d}_{\mathrm{rad}}-\mathrm{d}_{\mathrm{x}}\right)^{2}}{\mathrm{n}}},
$$

whereas $d_{\text {rad }}$ stands for the radial deformation of the detected PS, $d_{x}$ stands for the respective radial component of the closest in situ measurement, and $\mathrm{n}$ for the number of observations. In addition, the coefficient of determination

$$
\mathrm{r}^{2}=\frac{\operatorname{cov}(x, y)}{\sqrt{s_{x}^{2}-s_{y}^{2}}}
$$

was computed, forming the covariance between the two coefficient estimates $x$ and $y$ and the variances for the estimates, where $x$ represents the PSI measurement and $y$ the in situ measurement. Both $s_{x}^{2}$ and $s_{y}^{2}$ represent the variances of both values, respectively. Both statistic parameters were computed for each comparison of the PSI measurements with (a) the plumb measurements and (b) the trigonometric measurements.

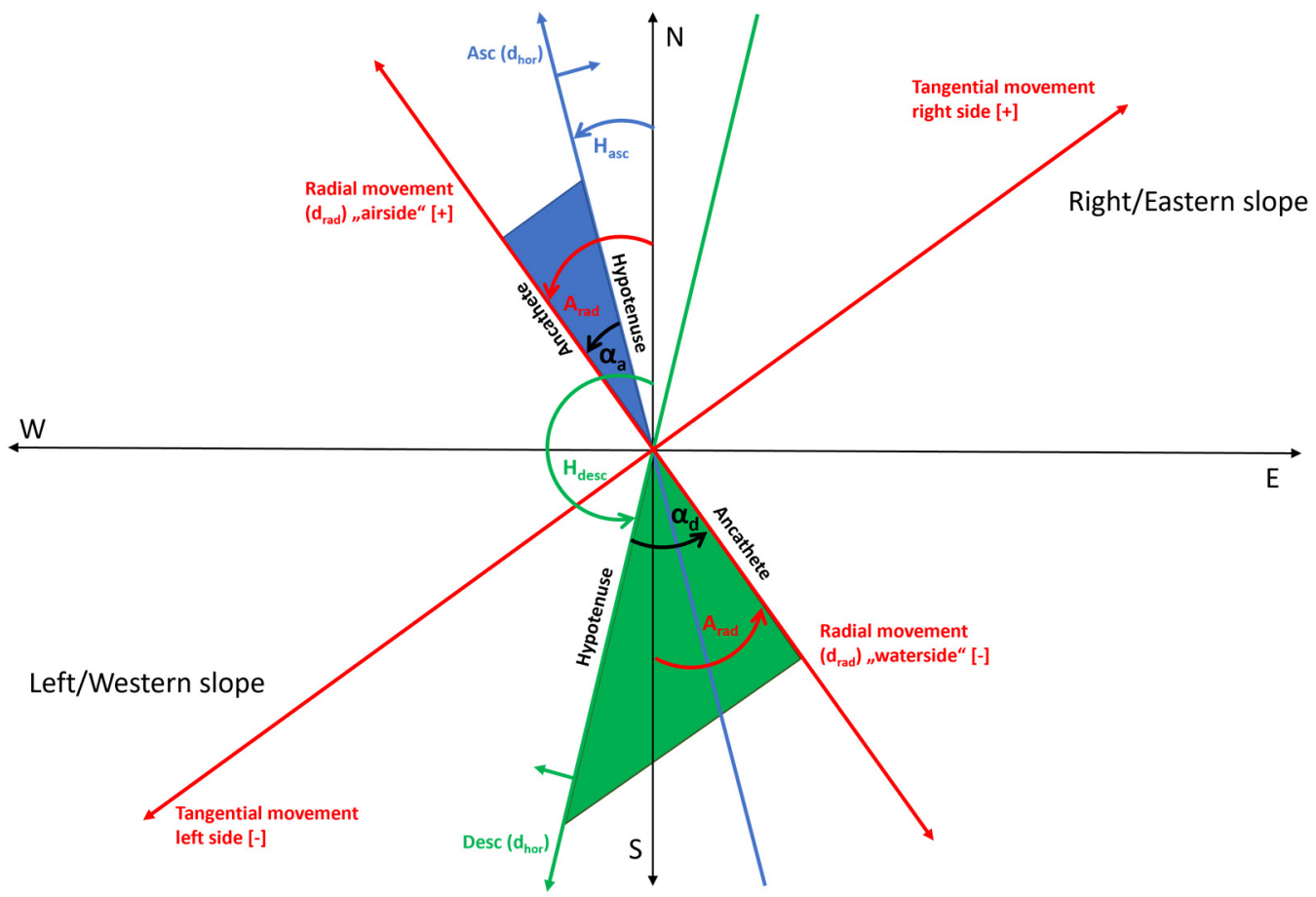

Figure 5. Illustration of the computation of the radial deformation in this study, applying the dam's precise model. Blue areas and lines correspond to the ascending direction, green to the descending direction, shown here for the sake of completeness.

\section{Results}

The presentation of the results is divided into three parts, starting with the influence of the observation frequency on the point density and followed by the presentation of estimation of radial deformation rates, and finally the accuracy assessment. This study focuses on the seasonal displacement of a gravity dam. Therefore, no velocity maps are shown, which is the case for most other PSI analyses.

\subsection{Frequency of Observation}

A total number of 29 PS points was identified along the Moehne gravity dam, utilizing all three Sentinel-1 data stacks mentioned in Table 1. Furthermore, Figure 6 displays the location of all 29 PS points and their respective Sentinel-1 data stack. The positions of the 
PS points presented in the following subsections (a3, a17, a18) are marked as well. Within these three stacks, the highest number of PS points was identified using the stack with the lowest number of scenes and vice versa. Hence, 5 out of 29 PS points were detected using the data stack $t_{3}$, which contains 164 Sentinel- 1 scenes, 11 points were detected using $t_{2}$, which contains 67 Sentinel-1 scenes, and 13 PS points were detected for the data stack containing 38 Sentinel-1 scenes. The PS points show different locations depending on the data stack, although most detected PS points are located on the dam crest with a significant accumulation near the towers, for all stacks. A small number of PS points are located at the lower parts of the dam and a few points lie further away from the dam.

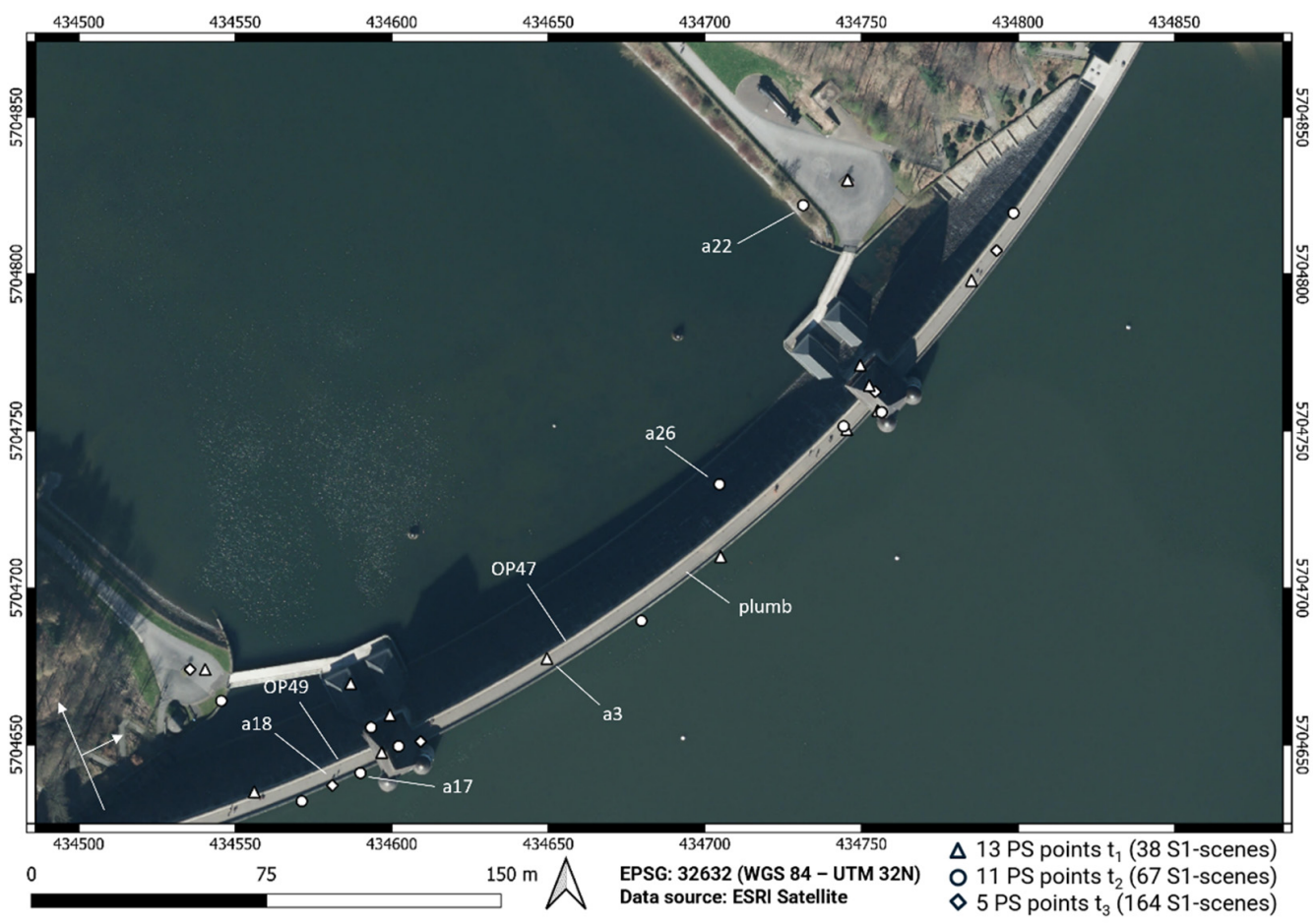

Figure 6. Overview of identified PS points. Shown are the points from all three data stacks of the ascending orbit $\left(t_{1}, t_{2}, t_{3}\right)$ combined as well as the locations of the relevant trigonometric measurements (OP47, OP49) and the plumb measurement. Sensor direction and beam direction of the ascending orbit are represented by two arrows in the lower left corner. Background image: ESRI Satellite.

Accuracies among the three data stacks do not differ significantly. Table 4 lists the RMSE and $r^{2}$ for a selection of PS points that are located on the dam crest compared to the plumb measurements. RMSE values move between $1.09 \mathrm{~mm}$ and $1.38 \mathrm{~mm}$ and are slightly lower for PS points from $t_{1}$. The $r^{2}$ values tend to be slightly higher for PS points from data stack $t_{1}$ as well. However, differences are small enough to be negligible.

\subsection{Deformation Patterns and Estimation of Radial Deformations}

Deformations were estimated for all 29 identified PS points, and LOS deformation was converted into horizontal and radial displacements according to Section 2.3. Furthermore, Figure 7 demonstrates the impact of the use of the precise dam model in order to compute the radial deformations. Maximum values, as well as minimum values, turn out to be less robust, whereas the seasonal pattern remains. In particular, the transition from LOS deformations into horizontal deformations causes the maximum and minimum values to reduce by up to $2 \mathrm{~mm}$. The same effect can be observed for the computation of radial deformations. Here, maximum values and minimum values reduced by up to another $0.5 \mathrm{~mm}$. The deformations regularly follow a seasonal pattern for all points. This pattern is shown in Figure 7 by the example of one PS point. In spring, the radial deformations generally reach a maximum of up to $3 \mathrm{~mm}$, whereas a decline in the following months 
can be observed, reaching a minimum during late summer of up to $-3.5 \mathrm{~mm}$. Solely in 2017 , the maximum values of radial deformation reached only about $1.2 \mathrm{~mm}$ in April. This seasonal cycle could be observed for all points that are located on the dam crest. The PS points that are located on the lower parts of the dam or near the outer parts and near the slopes contain the same seasonal pattern, but with significantly lower maximum and minimum displacement values.

Table 4. List of PS points that are located on the dam crest. Additionally provided is their respective data stack and statistical values. RMSE and $\mathrm{r}^{2}$ were computed using the PSI measurements and plumb measurements.

\begin{tabular}{cccc}
\hline PS Point & Data Stack & RMSE [mm] & $\mathbf{r}^{\mathbf{2}}$ \\
\hline $\mathrm{a} 2$ & $\mathrm{t}_{1}$ & 1.16 & 0.89 \\
$\mathrm{a} 3$ & $\mathrm{t}_{1}$ & 1.09 & 0.91 \\
$\mathrm{a} 4$ & $\mathrm{t}_{1}$ & 1.20 & 0.88 \\
$\mathrm{a} 5$ & $\mathrm{t}_{1}$ & 1.14 & 0.91 \\
$\mathrm{a} 6$ & $\mathrm{t}_{1}$ & 1.32 & 0.89 \\
$\mathrm{a} 8$ & $\mathrm{t}_{1}$ & 1.38 & 0.92 \\
$\mathrm{a} 15$ & $\mathrm{t}_{2}$ & 1.25 & 0.88 \\
$\mathrm{a} 21$ & $\mathrm{t}_{3}$ & 1.44 & 0.86 \\
$\mathrm{a} 24$ & $\mathrm{t}_{2}$ & 1.32 & 0.88 \\
$\mathrm{a} 25$ & $\mathrm{t}_{2}$ & 1.38 & 0.87 \\
$\mathrm{a} 27$ & $\mathrm{t}_{2}$ & 1.25 & 0.88 \\
$\mathrm{a} 29$ & $\mathrm{t}_{3}$ & 1.19 & 0.90 \\
\hline
\end{tabular}

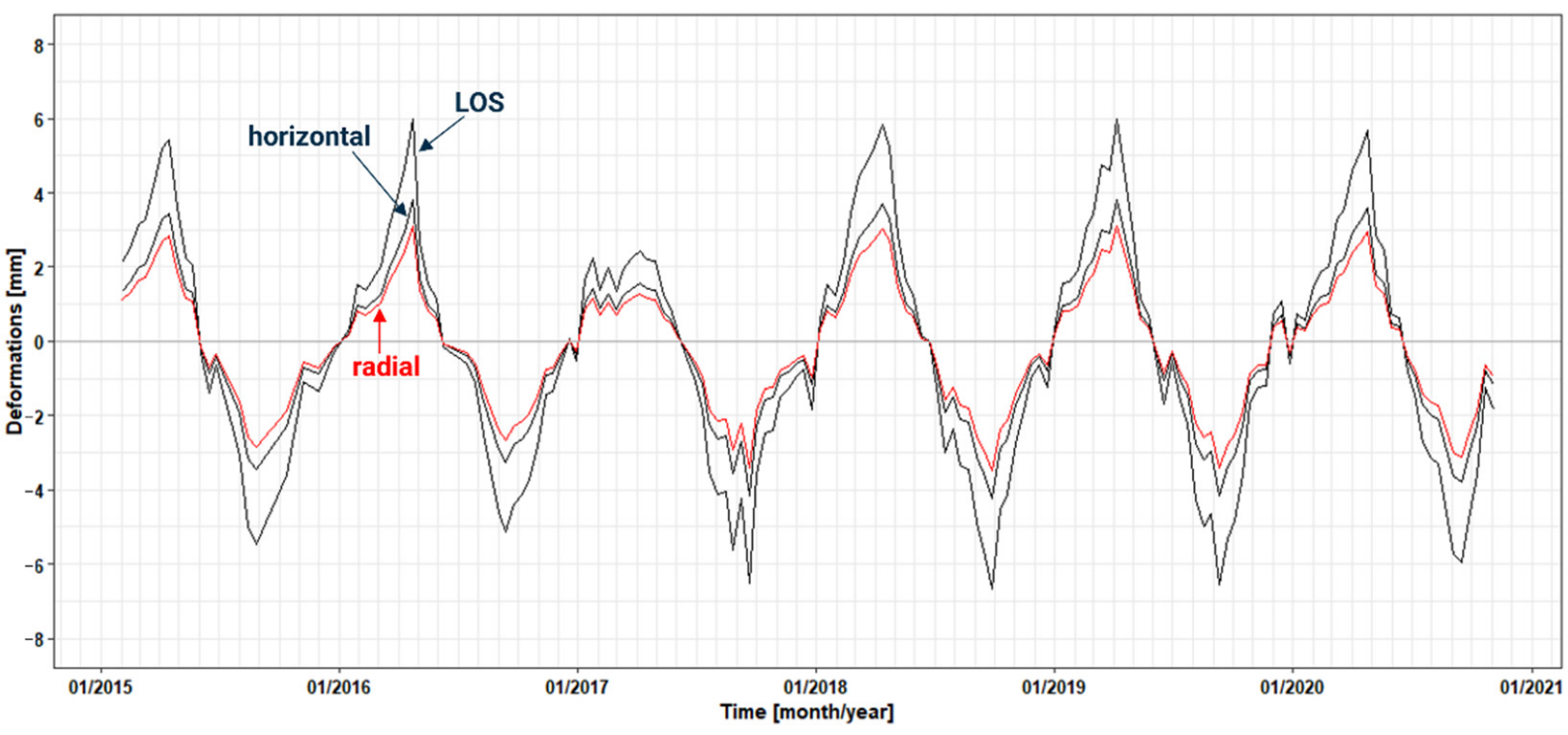

Figure 7. The seasonal pattern of the PSI measurement, as well as the water level, are similar to each other. This connection is confirmed by an $\mathrm{r}^{2}$ of 0.56 . Therefore, it is evident that the water level and subsequently the water pressure is the driving force of the deformation, although other factors may also have a more limited impact on the final deformation.

Additionally, the seasonal pattern could be correlated with the seasonal changes in the water level of the reservoir, as shown in Figure 8. The seasonal pattern of the PSI measurement, as well as the water level, are similar to each other. This connection is confirmed by an $\mathrm{r}^{2}$ of 0.56 . Therefore, it is evident that the water level and subsequently the water pressure is the driving force of the deformation, although other factors may also have a more limited impact on the final deformation. 


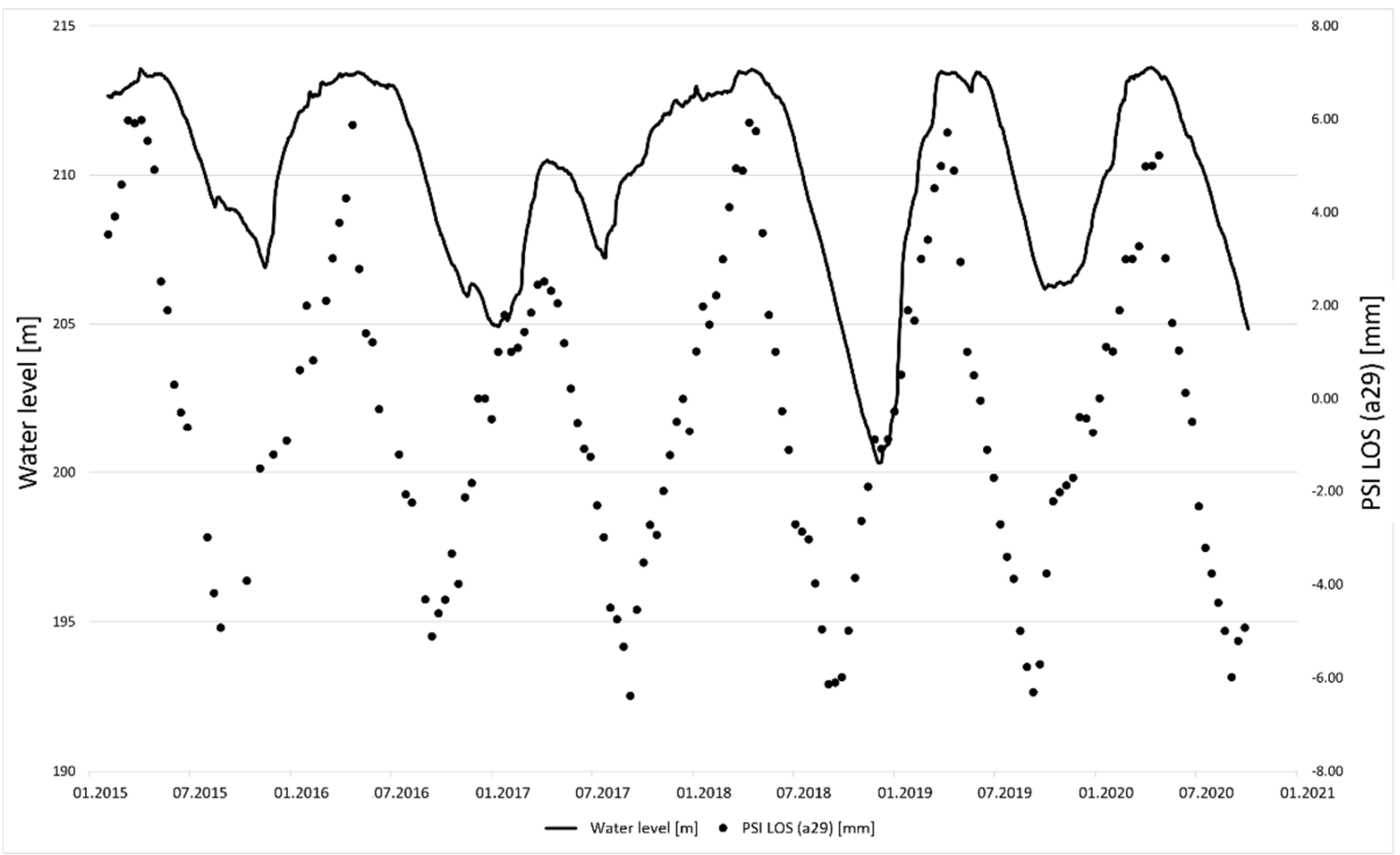

Figure 8. Comparison between PSI measurements and the water level of the Moehne lake. Seasonal patterns are similar to each other, and the connection between the two measurements is visible.

In the following section, results of the accuracy analyses using the radial deformations are presented.

\subsection{Accuracy Analysis}

The radial deformations were visually and statistically compared with the in situ measurements. Figure 9 illustrates the annual deformation rates for three single PS points, one out of each data stack, respectively. Additionally, plumb measurements and trigonometric measurements of the nearest measuring point are included. Since plumb measurements resolution is on a daily basis, the seasonal cycle can be tracked very simply.

Figure 9 a shows the PS point a from data stack $\mathrm{t}_{1}$, which contains 38 measurements. Despite the point density in the deformation profile being low, the seasonal cycle can be recognized and is comparable to the plumb measurements. Figure $9 \mathrm{~b}$ shows PS point a17, from the data stack containing 67 Sentinel- 1 scenes $\left(t_{2}\right)$. Similar to the previous example, the displacements follow a seasonal cycle, while PSI and plumb measurements show large visual similarities. Since this PS point was calculated from the data stack $t_{2}$, the point density is correspondingly higher than in Figure 9a. PS point a18 (Figure 9c), with its 164 measurements $\left(t_{3}\right)$, visually follows the profile of the plumb measurements in a seasonal cycle. The observation point density is the highest. Therefore, the seasonal cycle can be viewed in the most detail here and short-term deviations from the sinusoidal seasonal behavior can be better captured. However, as of April 2017, the values of the PSI measurements show a slight offset in time from the radial plumb measurements. This is manifested by the fact that the radial movements measured by the plumb reach their minimum points somewhat earlier, whereas the PS values lag behind and reach this point later. Since the other two data stacks contain a significantly lower number of observations, this effect cannot be traced so clearly.

In summary, the magnitude of the annual variation is clearly recognizable and in accordance with both the plumb measurements and the PS calculations of all three data stacks, where the seasonal cycles are similar and move between $-4 \mathrm{~mm}$ and $4 \mathrm{~mm}$ in their minima and maxima. 

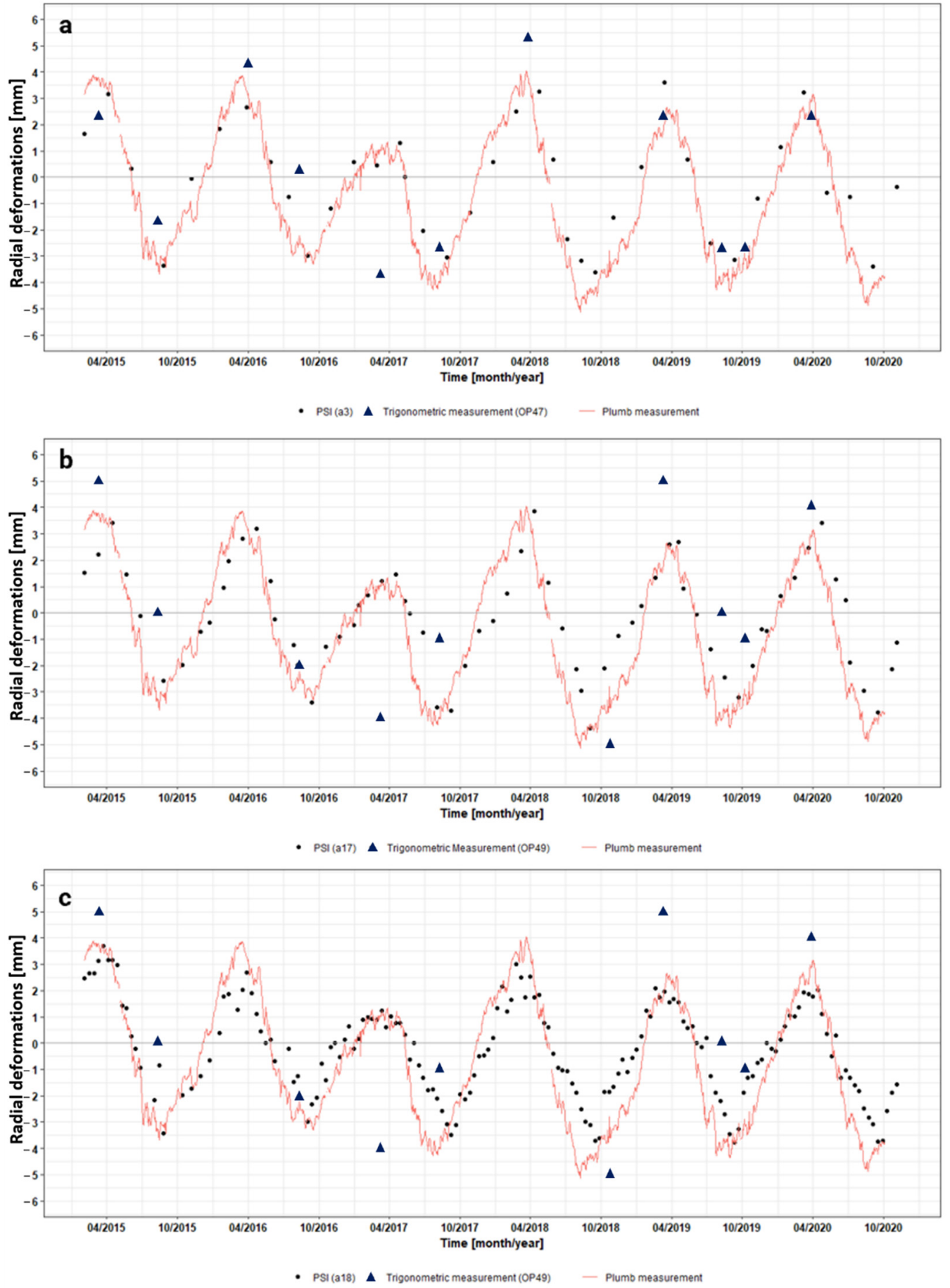

Figure 9. Visual comparison between three radial PSI deformations and the in situ measurements. Each point is taken out of one of the three data stacks, respectively. (a) PS point a17 from $t_{1}$; (b) PS point a17 from $t_{2} ;(c)$ PS point a18 from $t_{3}$.

The trigonometric measurements also show the seasonal cycle, which can be recognized by visual observation. It should be noted, however, that the values fluctuate significantly more in their minima and maxima. Since trigonometric measurements are only acquired twice a year at the Moehne dam, the significance of the visual comparison is also lower. The trigonometric measurements show very large deviations in all three cases, compared to the plumb and PSI measurements.

For a more detailed statistical analysis, Table 5 lists the basic statistical comparisons between PSI measurements and in situ measurements. 
Table 5. Accuracy measures for the three presented PS points in Figure 5. PSI measurements are compared to in situ measurements utilizing the RMSE and $\mathrm{r}^{2}$, respectively.

\begin{tabular}{ccccc}
\hline Point & $\begin{array}{c}\text { RMSE } \\
\text { (PSI-Plumb) }\end{array}$ & $\begin{array}{c}\text { RMSE } \\
\text { (PSI-Trig.) }\end{array}$ & $\begin{array}{c}\mathbf{r}^{\mathbf{2}} \\
\text { (PSI-Plumb) }\end{array}$ & $\begin{array}{c}\mathbf{r}^{\mathbf{2}} \\
\text { (PSI-Trig.) }\end{array}$ \\
\hline a3 $\left(\mathrm{t}_{1}\right)$ & $1.21 \mathrm{~mm}$ & $2.70 \mathrm{~mm}$ & 0.88 & 0.58 \\
a17 $\left(\mathrm{t}_{2}\right)$ & $1.20 \mathrm{~mm}$ & $2.93 \mathrm{~mm}$ & 0.91 & 0.77 \\
a18 $\left(\mathrm{t}_{3}\right)$ & $1.09 \mathrm{~mm}$ & $2.76 \mathrm{~mm}$ & 0.91 & 0.62 \\
\hline
\end{tabular}

The very low RMSE values (1.1-1.2 mm) and high $\mathrm{r}^{2}$ values for the comparison of PSI measurements and plumb measurements confirm the good conformity of those two measurements. Regarding the trigonometric measurements, consistencies with the PSI measurements are significantly lower, but still present. This is expressed through RMSE values that lie between $2.7 \mathrm{~mm}$ and $2.93 \mathrm{~mm}$ and $\mathrm{r}^{2}$ values that do not exceed a value of 0.77 . Only the results of three different points have been shown so far, however, a similar seasonal cycle, as well as the good matches with the plumb measurements, applies for all computed PS points that are located on top of the Moehne dam. This correlation is confirmed by Table 4 in Section 3.1, in which the statistical analysis is summarized for all relevant PS points.

As a further measure to evaluate the intrinsic accuracy of the technique, the statistical parameters of PS points that are clearly located far away from the dam, and for which no deformation is expected, can be considered. An example of PS 22 was provided in Figure 10. Additionally, the location of this point is given in Figure 6. It should be noted that these are the LOS values. Since their conversion to radial values is not useful due to their location outside the dam wall, the radial values are not shown. The points' deformations have maximum ranges of $2.25 \mathrm{~mm}$, compared to the range of $8 \mathrm{~mm}$ of the points situated on the dam. If no deformation exists at these points, these values can be used as another measure of the accuracy of the PSI technique. Thus, they indicate the basic uncertainty of the technique, which ranges around $+/-1.2 \mathrm{~mm}$. For this purpose, however, it should be ensured that no displacements or movements are actually present at these points, which could not be fully verified in this study.

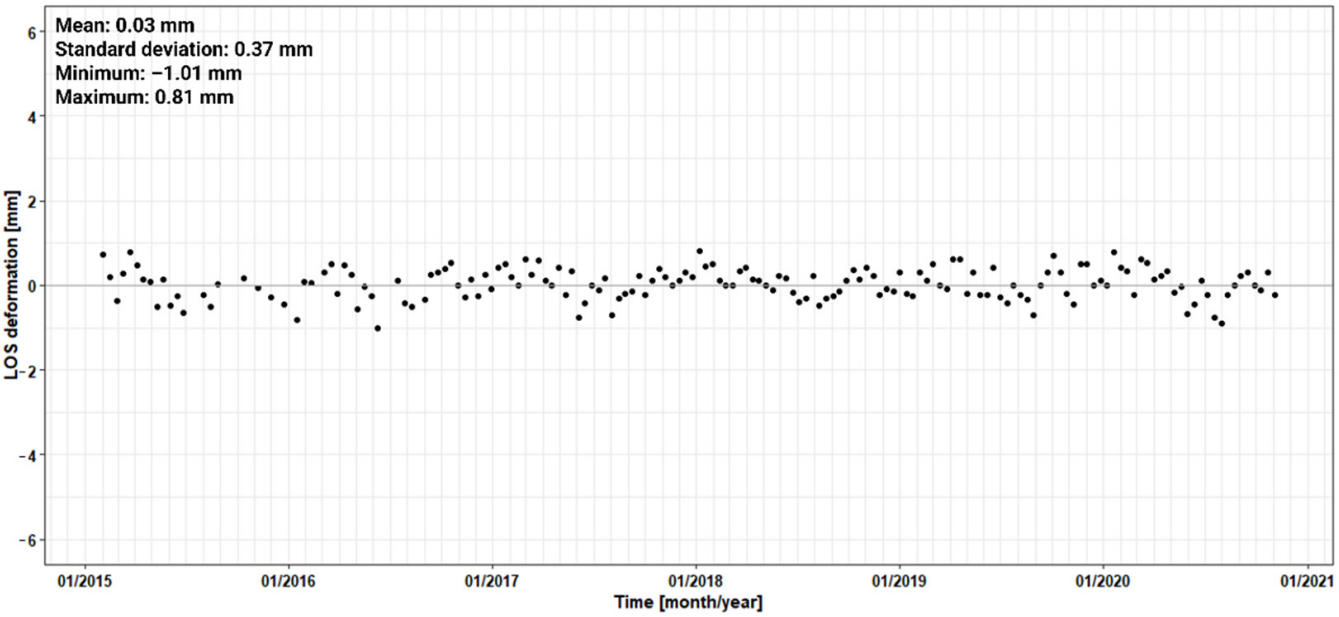

Figure 10. Deformation profile of a PS point located distant from the Moehne dam. Shown are the LOS deformations.

\section{Discussion}

In the following part, the results presented in the last chapter are discussed with respect to the goals defined at the beginning of this study.

To ensure the monitoring of the stability of the whole dam at as many points as possible, identification of a sufficient number of PS points is necessary. The higher the density and quality of the points, the more detailed the results. The physical properties of 
the objects located in the respective pixels form the most fundamental criteria for successful identification. Thus, high backscatter intensity and high phase stability are necessary for the identification of PS points. This is mostly true for certain land-cover classes, such as urban areas. Dams with their thickness and construction type also meet the requirements. In this study, the successful PSI-processing resulted in a total number of 29 PS points for all three stacks combined, which can be considered sufficient for dam monitoring of a gravity dam with a length of $650 \mathrm{~m}$ and height of $40 \mathrm{~m}$ using the PSI technique. As a comparison, 27 trigonometric observation points are used for monitoring this dam. The PS scores resulting from these three data stacks differ greatly. For the analysis, a total of 164 available scenes were used in one analysis, and in two other data stacks, this number was reduced to 67 and 38 scenes, respectively. Only five PS points were identified for the data stack with the highest data density $\left(t_{3}\right)$, while 11 and 13 PS points were identified for the two data stacks with lower data densities $\left(t_{2}\right.$ and $\left.t_{1}\right)$. Therefore, a connection between the observation frequency and the number of resulting PS points could be made. Although no major differences are apparent between the location of the points from each data stack, the fact that the most points were identified with the use of the least amount of data is noteworthy. No definitive explanations for this phenomenon can be given at this point, only some thoughts based on the nature of the technique. A reduction in PS points when using a lot of data could be due to momentary perturbations that occurred while one of the scenes was being recorded, yielding an unstable signal at specific point positions, thereby hampering the PS detection. Satellite missions, such as Sentinel-1 or NISAR, have led to the availability of huge amounts of data, which brings new challenges at the same time. The impact of big data volumes on the quality of multitemporal InSAR methods has already been highlighted in various studies $[37,38]$. The developed technique of the so-called sequential estimator [37] provides an approach to divide and compress a large amount of available data into smaller sections. From here, the multitemporal interferograms are then formed and used for further analysis. On the one hand, scenes, which would carry disturbing influences into an analysis, can be eliminated and on the other hand, the analysis is more effective in terms of time, since fewer scenes are used [37]. Because of the division of the entire period, it is also not necessary to reprocess the entire data set for a new SAR scene [37]. First results from [37] show a compromise of a slightly lower accuracy and significantly reduced the computational time or effort in the application for this methodology. Due to the phenomena occurring during the observation of the Moehne dam, the Sequential Estimator can be used as an alternative technique and could be investigated with regard to whether it fulfills the necessary accuracy requirements whilst keeping more PSs.

Additionally, the detected points are situated around prominent features such as the towers, providing fewer observations for the monitoring of other parts of the dam. However, since the scale of the deformations is equal for all parts of the upper dam [27], PSI deformations measured at the towers can be transferred to areas with a lesser PS point density. In particular, points located on the large towers of the Möhne dam show the same dynamics as those points that are located, e.g., in the middle of the dam. There is, however, a variability of the PS measurements that relates to the altitude of the PS points on the dam. Lower points on the airside show significantly lower minima and maxima. Figure 11 shows an example of a PS point from the lower parts of the dam, compared to the plumb measurement situated on the top of the wall. This point has a height of $190 \mathrm{~m}$ and is therefore, located about $20 \mathrm{~m}$ lower than the points on the dam crest.

The PS point a26 is located far below the dam crest (see Figure 6). This indicates that the movements of the dam in the lower part are significantly smaller. This correlation is confirmed by other studies [3,39], which describe the deformation of a dam as a function of water pressure and the dams' design. Though the water pressure is the driving factor for displacement, the dams' design is not to be neglected. Although the water pressure for the dam crest is lower compared to the dam foot, deformations are higher, whereas the deformation decreases towards the foundation of the dam. This connection is confirmed by points located on the lower parts of the dam. They show significantly smaller movement 
rates. Additional points that show significantly lower movement rates are those PS points, which are located on the outer parts of the wall. Even though a majority of these points appear to be located on the upper part of the wall, they show low values in their seasonal patterns that are comparable to those in Figure 11. Therefore, by utilizing the PSI technique at the Moehne gravity dam, varieties in deformation rates due to the walls' design, structure and response to water pressure were visible.

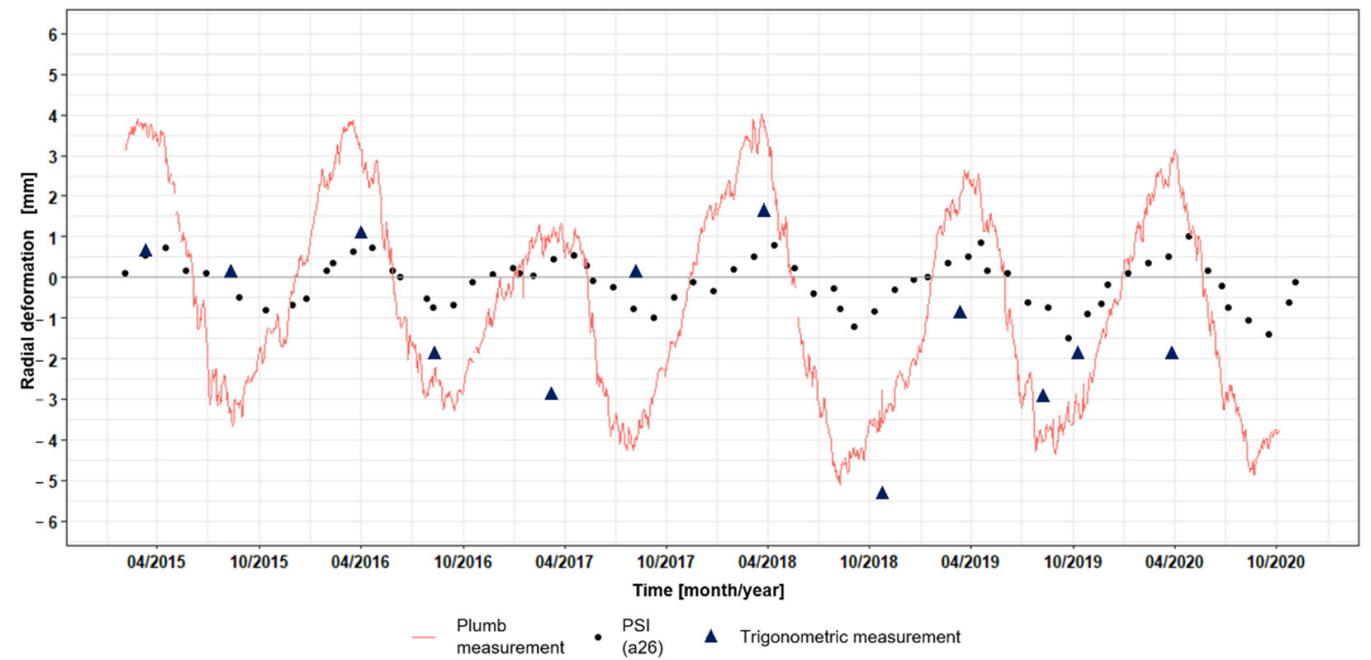

Figure 11. Deformation profile of a PS point (a26) located at the dam's lower part and the comparison with in situ measurements.

To evaluate the applicability of the PSI technique on gravity dams following the example of the Moehne dam, a variety of points can be discussed in this paper. Firstly, a direct comparison with the in situ measurements is discussed. The results of the accuracy analysis have shown that especially the plumb measurements are very well related to the obtained PSI results. All PS points, which are assumed to be located on top of the wall, show very similar courses to the plumb measurements over the whole observation period. This is also confirmed by the statistical analysis, which provides $r^{2}$ values in the range of 0.88 to 0.95 for all PS points. The RMSEs are also very small, with values in the range between $1.1 \mathrm{~mm}$ and $1.2 \mathrm{~mm}$. Thus, the results of the validation of the PSI analysis with the plumb measurements, which are the most accurate terrestrial measurements, can be described as very good and PSI could be used to monitor gravity dams according to DIN requirements on a more regular basis than current terrestrial measurements.

The results of the comparisons with the trigonometric data generally give significantly worse results than the comparisons with the plumb measurements. While the visual comparison shows many measurement points that agree well with the PSI measurements, there are also a large number of deviations of up to several millimeters. This is mainly due to the inaccurate measuring method compared to the plumb measurements (see Table 2). Its uncertainty is obtained with a confidence range of $+/-3 \mathrm{~mm}$, whereas the measuring accuracy of the plumb measurement is noted with $+/-0.5 \mathrm{~mm}$ [27]. Because of this, the RMSE values are also significantly increased and the $\mathrm{r}^{2}$ values are generally significantly smaller. However, it must also be considered that only 12 or fewer trigonometric measurements were available for the observation period, since this measurement was taken only twice a year. In summary, it can be noted that a comparison of the PSI measurements with the trigonometric points is limited due to the low temporal coverage and the low accuracy, providing, however, a good spatial representation of the dam wall. The plumb measurement, on the other hand, only takes place at one point on the wall. The results of the accuracy analysis provided plausible results showing that the PSI technique is a powerful tool for calculating displacements and monitoring gravity dams with sufficient accuracy.

The successful accuracy analysis was made possible with the use of a precise dam model to calculate the radial deformation rates. PSI deformation measurements refer to the 
LOS alignment of the SAR sensor $[40,41]$. Since deformations are generally 3D phenomena, it is essential to note that the PSI technique only reflects a combination of those dimensions into one dimension (LOS) [42]. One of the crucial points in the application of the PSI technique is the extraction of the vertical and horizontal movements, respectively [43,44]. A large number of studies from different application areas use ascending and descending data in combination to achieve this goal and extend the LOS values to a 2D context [36,45-48]. Moreover, it is also clear from all these studies that this kind of extraction is only possible when data from both flight directions are available [49] at similar point locations. However, this limitation refers only to situations in which both directions of motion, vertical and horizontal, are significantly present. Since in the case of the Moehne dam the vertical movements can be neglected [26], an extraction of the horizontal movements, as described in the methods chapter is possible, assuming that all the measured deformation in LOS corresponds to a radial displacement. It is worth mentioning that only a radial deformation occurring in East/West direction can be retrieved precisely with spaceborne PSI technique.

For future analyses, however, it is necessary to distinguish the goal in terms of the amount of used data. Since the accuracy for all data stacks remains nearly the same, it is also valuable to use fewer data. In this case, the number of resulting PS points is higher, however, seasonal changes cannot be captured that well. Using all available data, as was done in $t_{3}$, only a few PS points were identified. Therefore, the dam was not fully spatially covered. If a temporal resolution such as that of the $t_{1}$ or $t_{2}$ data stack is sufficient, this resolution should be preferred since accuracies are similar. It is also indicated that with less Sentinel-1 data, more PS-points could be identified and therefore, a higher spatial coverage of the Moehne dam could be achieved. The accuracies of the movements of the three data stacks are similar, but it should be noted that the temporal offset in data stack $t_{3}$ of up to a few weeks, which is particularly evident from the visual comparison with the plumb measurements, is not to be neglected. This can also explain the higher RMSE and the slightly lower $r^{2}$; values in comparison to the values of the PS points from the other data stacks. In summary, all three data stacks delivered good results. The accuracies of all three data stacks are good enough for a PSI analysis.

Finally, comparing the water level in the reservoir with the deformation, a good correlation is recognizable. However, it seems from Figure 8 that the PSI deformation systematically begins before the water level of the dam arises on all occasions. This observed phenomenon will be object of future investigation.

\section{Conclusions}

In this work, the PSI technique was successfully and cost-effectively applied to the Moehne dam. Data of the ascending orbit were analyzed and validated with the in situ terrestrial measurements of the Ruhrverband. Seasonal radial deformations of up to $+/-4 \mathrm{~mm}$ could be detected over the observation period. Validation of the displacements calculated by the PSI analysis with the in situ data of the Moehne gravity dam yielded high-quality results and showed the high accuracy of the technique for regular monitoring of gravity dams, with the accuracies being in accordance with DIN. These results show that the PSI technique is suitable for the monitoring of the gravity dam and fulfill the first goal of this study. Furthermore, many PS points could be identified, with the number of PS points varying with the number of scenes considered. In particular, the number of detected PSs decreased with an increasing observation frequency. As the measurement accuracy between all datasets does not vary by much, one could decide either to monitor dam deformations with a higher spatial density of observation points using less scenes, or with a higher temporal density using all scenes. The first option comes at the expense of the temporal density of the displacement information, the second at the expense of the spatial distribution of the PS observations.

Through a visual comparison of the PSI measurements with the in situ measurements of the Ruhrverband, a seasonal cycle was visible, which was characterized by high correlations and low RMSE in the statistical evaluation The movements of dams are highly 
complex and influenced by various factors, such as the mean air temperature of the past days, as well as the water level in the reservoir, which itself is influenced by precipitation and the water management of the reservoir. The correlation and interaction of those factors will be the object of further studies. By including experts in the field of dam design and operation, in future research, highly complex interactions which influence the movements of gravity dams will be analyzed.

Author Contributions: Conceptualization, J.J. and C.D.; methodology, J.J. and C.D.; software, J.J.; validation, J.J.; formal analysis, J.J., J.B. and C.D.; investigation, J.J., V.B. and C.D.; resources, V.B. and K.L.; data curation, J.J.; writing-original draft preparation, J.J. and C.D.; writing-review and editing, J.J., C.S., J.B., V.B., K.L. and C.D.; visualization, J.J.; supervision, C.D.; project administration, C.D. All authors have read and agreed to the published version of the manuscript.

Funding: This research received no external funding.

Data Availability Statement: The data presented in this study are available on request from the corresponding author. The data are not publicly available due to legal and privacy issues.

Conflicts of Interest: The authors declare no conflict of interest.

\section{References}

1. Ruhrverband. Bauweise \& Funktionsweise von Talsperren. Available online: https://www.ruhrverband.de/fluesse-seen/ talsperren/bau-funktionsweise/ (accessed on 10 January 2022).

2. Ruhrverband. Technische Angaben: Möhnetalsperre. Available online: https://www.ruhrverband.de/fluesse-seen/talsperren/ moehnetalsperre/technische-angaben/ (accessed on 10 January 2022).

3. Gebler, T. Statistische Auswertung von Simulierten Talsperrenüberwachungsdaten zur Identifikation von Schadensprozessen an Gewichtsstaumauern. Ph.D. Thesis, University of Stuttgart, Stuttgart, Germany, October 2018. Available online: https://henry.baw. de/bitstream/handle/20.500.11970/106486/262_Gebler_Tobias_Statistische\%20Auswertung.pdf?sequence=1\&isAllowed=y (accessed on 10 January 2022).

4. Otto, H.P. Überwachungsmessungen an Talsperren. Hochschule für Technik, Wirtschaft und Kultur Leipzig (FH), Fachbereich Bauwesen, Lehrgebiet Vermessungskunde. Available online: http://webarchiv.ethz.ch/geometh-data/student/eg1/2006/06 /Otto\%20Leipzig-Staumauern.pdf (accessed on 10 January 2022).

5. German Institute of Standardization. DIN 19700-10: 2004-07, Stauanlagen—Teil 10: Gemeinsame Festlegungen; Beuth Verlag GmbH: Berlin, Germany, 2004.

6. Bettzieche, V. Mathematisch-Statistische Analyse von Messwerten der Talsperrenüberwachung. Wasserwirtschaft 2004, 94, 30-34. [CrossRef]

7. Ferretti, A.; Prati, C.; Rocca, F. Permanent scatterers in SAR interferometry. IEEE Trans. Geosci. Remote Sens. 2001, 39, 8-20. [CrossRef]

8. Ferretti, A.; Prati, C.; Rocca, F. Nonlinear subsidence rate estimation using permanent scatterers in differential SAR interferometry IEEE Trans. Geosci. Remote Sens. 2000, 38, 2202-2212. [CrossRef]

9. Emadali, L.; Motagh, M. Long-term deformation analysis of Masjed-Soleyman rockfill dam (Iran): Results based on terrestrial geodect data. Earth Obs. Geomat. Eng. 2020, 4, 26-43. [CrossRef]

10. Mura, J.; Gama, F.; Paradella, W.; Negrao, P.; Carneiro, S.; de Oliveira, C.; Brandao, W. Monitoring the Vulnerability of the Dam and Dikes in Germano Iron Mining Area after the Collapse of the Tailings Dam of Fundao (Mariana-MG, Brazil) Using DInSAR Techniques with TerraSAR-X Data. Remote Sens. 2018, 10, 1507. [CrossRef]

11. Othman, A.A.; Al-Maamar, A.F.; Al-Manmi, D.A.M.; Liesenberg, V.; Hasan, S.E.; Al-Saady, Y.I.; Shihab, A.T.; Khwedim, K. Application of DInSAR-PSI Technology for Deformation Monitoring of the Mosul Dam, Iraq. Remote Sens. 2019, $11,2632$. [CrossRef]

12. Mazzanti, P.; Perissin, D.; Rocca, A. Structural health monitoring of dams by advanced satellite SAR interferometry: Investigation of past processes and future monitoring perspectives. In Proceedings of the 7th International Conference on Structural Health Monitoring of Intelligent Infrastructure, Torino, Italy, 1-3 July 2015.

13. Lazecký, M.; Perissin, D.; Zhiying, W.; Ling, L.; Yuxiao, Q. Observing Dam's Movements with Spaceborne SAR Interferometry In Engineering Geology for Society and Territory; Lollino, G., Manconi, A., Guzzetti, F., Culshaw, M., Bobrowsky, P., Luino, F., Eds.; Springer: Cham, Switzerland; Heidelberg, Germany; New York, NY, USA; Dordrecht, The Netherlands; London, UK; Basel, Switzerland, 2015; Volume 5, pp. 131-136. [CrossRef]

14. Lazecký, M.; Perissin, D.; Wang, Z.; Lei, L.; Qin, Y. Observing Dam's Movements with Spaceborne SAR Interferometry: Conference Paper. Proc. Eng. Geol. Soc. Territ. 2015, 5, 131-136.

15. Wang, T.; Perissin, D.; Rocca, F.; Liao, M.-S. Three Gorges Dam stability monitoring with time-series InSAR image analysis. Sci. China Earth Sci. 2011, 54, 720-732. [CrossRef] 
16. Ruiz-Armenteros, A.M.; Lazecky, M.; Hlaváčová, I.; Bakoň, M.; Delgado, J.M.; Sousa, J.J.; Lamas-Fernandez, F.; Marchamalo, M.; Caro-Cuenca, M.; Papco, J.; et al. Deformation monitoring of dam infrastructures via spaceborne MT-InSAR. The case of La Vinuela (Malaga, southern Spain). Procedia Comput. Sci. 2018, 138, 346-353. [CrossRef]

17. Milillo, P.; Bürgmann, R.; Lundgren, P.; Salzer, J.; Perissin, D.; Fielding, E.; Biondi, F.; Milillo, G. Space Geodetic monitoring of engineered structures: The ongoing destabilization of the Mosul dam, Iraq. Sci. Rep. 2016, 6, 37408. [CrossRef]

18. Milillo, P.; Porcu, M.C.; Lundgren, P.; Soccodato, F.; Salzer, J.; Fielding, E.; Bürgmann, R.; Milillo, G.; Perissin, D.; Biondi, F. The Ongoing Destabilization of the Mosul Dam as observed by Synthetic Aperture Radar Interferometry. In Proceedings of the IEEE International Geoscience and Remote Sensing Symposium (IGARSS), Fort Worth, TX, USA, 23-28 July 2017; pp. 6279-6282. [CrossRef]

19. Evers, M.; Kyriou, A.; Thiele, A.; Hammer, H.; Nikolakopoulus, K.; Schulz, K. How to set up a dam monitoring system with PSInSAR and GPS. SPIE Remote Sens. 2020, 11534, 115340L. [CrossRef]

20. Schneider, P.; Soergel, U. Monitoring Einer Schleuse Mittels Persistent-Scatterer-Interferometrie. 40. Wissenschaftlich-Technische Jahrestagung der DGPF in Stuttgart-Publikationen der DGPF, Band 29, 448-456. Available online: https://www.dgpf.de/src/ tagung/jt2020/proceedings/proceedings/papers/64_DGPF2020_Schneider_Soergel.pdf (accessed on 10 January 2022).

21. Antonielle, B.; Caporossi, P.; Mazzanti, P.; Moretto, S.; Rocca, A. InSAR \& Photomonitoring ${ }^{\mathrm{TM}}$ for Dams and Reservoir Slopes Health \& Safety Monitoring. In Proceedings of the Twenty-Sixth Congress on Large Dams 2018, Commission Internationale des Grands Barrages, Vienna, Austria, 1-7 July 2018; pp. 4-6.

22. Mazzanti, P.; Antonielli, B.; Sciortino, A.; Scancella, S.; Bozzano, F. Tracking Deformation Processes at the Legnica Glogow Copper District (Poland) by Satellite InSAR-II: Zelazny Most Tailings Dam. Land 2021, 10, 654. [CrossRef]

23. Scaioni, M.; Marsella, M.; Crosetto, M.; Tornatore, V.; Wang, J. Geodetic and Remote-Sensing Sensors for Dam Deformation Monitoring. Sensors 2018, 18, 3682. [CrossRef] [PubMed]

24. Bettzieche, V. Satellitenüberwachung der Verformungen von Staumauern und Staudämmen. Wasserwirtschaft 2020, 9, 48-51. [CrossRef]

25. Ruhrverband. Talsperrenleitzentrale des Ruhrverbands. Möhnetalsperre. Available online: https://www.talsperrenleitzentraleruhr.de/online-daten/webcams/webcam_moehne/ (accessed on 23 February 2022).

26. Ruhrverband. Möhnetalsperre. Sicherheitsbericht. Teil A, 2013; Unpublished security report.

27. Ruhrverband. Möhnetalsperre. Vertiefte Überprüfung. Anal. Messdaten, 2018; Unpublished security report.

28. Ruhrverband. Die Möhnetalsperre. Available online: https://www.ruhrverband.de/fluesse-seen/talsperren/moehnetalsperre/ (accessed on 10 January 2022).

29. Cigna, F.; Bateson, L.B.; Jordan, C.J.; Dashwood, C. Simulating SAR geometric distortions and predicting Persistent Scatterer densities for ERS-1/2 and ENVISAT C-band SAR and InSAR applications: Nationwide feasibility assessment to monitor the landmass of Great Britain with SAR imagery. Remote Sens. Environ. 2014, 152, 441-446. [CrossRef]

30. Notti, D.; Meisina, C.; Zucca, F.; Colombo, A. Models to Predict Persistent Scatterers Data Distribution and Their Capacity to Register Movement Along the Slope. Fringe 2011 Workshop, 19-23. Available online: https://earth.esa.int/eogateway/ documents/20142/37627/Models_predict_persistent_scatterers_data_distribution.pdf (accessed on 10 January 2022).

31. Ruhrverband. Aerial Photo and drafts of the Moehne Gravity Dam. 2020; Unpublished material.

32. GDI-NW. Geodateninfrastruktur Nordrhein-Westfalen. Available online: https://www.geoportal.nrw/gdi-nw (accessed on 10 January 2022).

33. Ruhrverband. Measuring Data. 2020; Unpublished dataset.

34. Alba, M.; Bernardini, G.; Giussani, A.; Ricc, P.P.; Roncoroni, F.; Scaioni, M.; Valgoi, P.; Zhang, K. Measurement of Dam Deformations by Terrestrial Interferometric Techniques. Int. Arch. Photogramm. Remote Sens. Spat. Inf. Sci. 2008, 37, 133-139.

35. Wegmuller, U.; Werner, C.; Wiesmann, A.; Strozzi, T.; Santoro, M.; Frei, O.; Schwank, M.; Caduff, R.; Cartus, O.; Magnard, C.; et al. Gamma; Gamma Remote Sensing: Gümlingen, Switzerland, 2021.

36. Fuhrmann, T.; Garthwaite, M.C. Resolving Three-Dimensional Surface Motion with InSAR: Constraints from Multi-Geometry Data Fusion. Remote Sens. 2019, 11, 241. [CrossRef]

37. Ansari, H.; de Zan, F.; Bamler, R. Sequential estimator: A novel approach for efficient high-precision analysis of interferometric time series. In Proceedings of the IEEE International Geoscience and Remote Sensing Symposium (IGARSS), Fort Worth, TX, USA, 23-28 July 2017; pp. 980-983. [CrossRef]

38. Ansari, H.; de Zan, F.; Parizzi, A. Study of Systematic Bias in Measuring Surface Deformation With SAR Interferometry. IEEE Trans. Geosci. Remote Sens. 2021, 59, 1285-1301. [CrossRef]

39. Herzog, M.A.M. Elementare Talsperrenstatik: Mit 26 Zahlenbeispielen von Ausgeführten Talpserren im Vergleich zum Gemessenen Verhalten; Werner Verlag: Düsseldorf, Germany, 1998; ISBN 3804120709.

40. Adam, N.; Gonzalez, F.R.; Parizzi, A.; Brcic, R. Wide area Persistent Scatterer Interferometry: Current developments, algorithms and examples. In Proceedings of the IEEE International Geoscience and Remote Sensing Symposium (IGARSS), Melbourne, VIC, Australia, 27 January 2014; pp. 1857-1860. [CrossRef]

41. Yu, L.; Yang, T.; Zhao, Q.; Liu, M.; Pepe, A. The 2015-2016 Ground Displacements of the Shanghai coastal Area Inferred from a Combined COSMO-SkyMed/Sentinel-1 DInSAR Analysis. Remote Sens. 2017, 9, 1194. [CrossRef]

42. Crosetto, M.; Monserrat, O.; Cuevas-González, M.; Devanthéry, N.; Crippa, B. Persistent Scatterer Interferometry: A review. ISPRS J. Photogramm. Remote Sens. 2016, 115, 78-89. [CrossRef] 
43. Salepci, N. Multi-Sensor Synergy for Persistent Scatterer Interferometry Based Ground Subsidence Monitoring. Ph.D. Thesis, Friedrich Schiller University Jena, Jena, Germany, 2014.

44. Vassileva, M.; Giulio Tonolo, F.; Riccardi, P.; Lecci, D.; Boccardo, P.; Chiesa, G. Satellite SAR interferometric techniques in support to emergency mapping. Eur. J. Remote Sens. 2017, 50, 464-477. [CrossRef]

45. Ferretti, A.; Monti-Guarnieri, A.; Prait, C.; Rocca, F. InSAR Principles: Guidelines for SAR Interferometry Processing and Interpretation; ESA Publications: Noordwijk, The Netherlands, 2007.

46. Bechor, N.B.D.; Zebker, H.A. Measuring two-dimensional movements using a single InSAR pair. Geophys. Res. Lett. 2006, 33, 1355. [CrossRef]

47. Aslan, G.; Foumelis, M.; Raucoules, D.; de Michele, M.; Bernardie, S.; Cakir, Z. Landslide Mapping and Monitoring Using Persistent Scatterer Interferometry (PSI) Technique in the French Alps. Remote Sens. 2020, 12, 1305. [CrossRef]

48. Mora, O.; Ordoqui, P.; Iglesias, R.; Blanco, P. Earthquake Rapid Mapping Using Ascending and Descending Sentinel-1 TOPSAR Interferograms. Procedia Comput. Sci. 2016, 100, 1135-1140. [CrossRef]

49. Hu, J.; Li, Z.W.; Ding, X.L.; Zhu, J.J.; Zhang, L.; Sun, Q. Resolving three-dimensional surface displacements from InSAR measurements: A review. Earth-Sci. Rev. 2014, 133, 1-17. [CrossRef] 